\title{
Conspecific presence, but not pilferage, influences pinyon jays' (Gymnorhinus cyanocephalus) caching behavior
}

\author{
Alizée Vernouillet ${ }^{1}$ • Hera J. M. Casidsid ${ }^{2}$ - Debbie M. Kelly ${ }^{1,2}$ \\ Accepted: 3 November 2020 / Published online: 2 December 2020 \\ (C) The Psychonomic Society, Inc. 2020
}

\begin{abstract}
Caching species store food when plentiful to ensure availability when resources are scarce. These stores may be at risk of pilferage by others present at the time of caching. Cachers may reduce the risk of loss by using information from the social environment to engage in behaviors to secure the resource-cache protection strategies. Here, we examined whether pinyon jays, a highly social corvid, use information from the social environment to modify their caching behavior. Pinyon jays were provided with pine seeds to cache in two visually distinct trays. The cacher could be observed by a non-pilfering conspecific, a pilfering conspecific, or an inanimate heterospecific located in an adjoining cage compartment, or the cacher could be alone. After caching, the pilfered tray was placed in the adjoining compartment where caches were either pilfered (pilfering conspecific and inanimate heterospecific conditions) or remained intact (non-pilfering conspecific and alone conditions). The safe tray was placed in a visible, but inaccessible, location. Overall, pinyon jays reduced the number of pine seeds cached in the pilfered tray when observed, compared with caching alone. However, their caching behavior did not differ between the pilfering conspecific and the non-pilfering conspecific conditions. These results suggest that either pinyon jays were unable to discriminate between the pilfering and non-pilfering conspecifics, or they generalized their experience of risk from the pilfering conspecific to the nonpilfering conspecific. Thus, we report evidence that pinyon jays use cache protection strategies to secure their resources when observed, but respond similarly when observed by pilfering and non-pilfering conspecifics.
\end{abstract}

Keywords Cache protection strategies $\cdot$ Corvids $\cdot$ Pilfering $\cdot$ Pinyon jays $\cdot$ Social context

Irene M. Pepperberg's pioneering research with the languagetrained grey parrots (Psittacus erithacus), Alex, and more recently Griffin and Athena, has deepened our understanding of avian cognition. Over several decades, the groundbreaking results obtained from Pepperberg and her research team have challenged many preconceived ideas that complex cognitive abilities, such as numerosity (reviewed by Pepperberg, 2006a, 2006b), category comprehension (e.g., Pepperberg, 1990), and abstract concept learning (reviewed by Pepperberg, 2013), are exclusive to primates. These investigations, and the insights they provided, contributed to the growth of the field of comparative cognition, by expanding the breadth of species examined and the research areas investigated, revealing impressive

Debbie M. Kelly

debbie.kelly@umanitoba.ca

1 Department of Biological Sciences, University of Manitoba, Winnipeg, MB R3T 2N2, Canada

2 Department of Psychology, University of Manitoba, 190 Dysart Rd, Winnipeg, MB R3T 2N2, Canada cognitive abilities particularly among parrots and corvids (reviewed by Cussen, 2017; Emery \& Clayton, 2004; Lambert, Jacobs, Osvath, \& von Bayern, 2018).

The complexity of social life has been argued as a factor contributing to the evolution of cognitive abilities (e.g., Humphrey, 1976). Although initially proposed to account for these facilities in primates, many social qualities (e.g., large, semipermanent groups or fission-fusion situations, long-lived individuals, or extended developmental periods) exist within other animal groups. Likewise, the demands of living in social groups (such as learning about the relationships among multiple individuals) may be experienced by non-primate species. For example, many studies have shown impressive sociocognitive abilities by several corvid species (e.g., for reviews, see Bugnyar, 2013; Dally, Emery, \& Clayton, 2010).

Food-caching, the behavior of storing food when plentiful to ensure availability of nourishment when resources are scarce, is a natural behavior often used during investigations of the sociocognitive abilities of corvids (e.g., Clary, \& Kelly, 2011; Emery \& Clayton, 2001). Two important components 
involved in food-caching are spatial memory, remembering where (and possibly when) an item was stored (reviewed by Gould, Kelly, \& Kamil, 2010; Pravosudov \& Smulders, 2010), and securing the food store - for instance, protecting the resource against pilferage (reviewed by Bugnyar, 2013; Dally, Emery, Clayton, 2006a; Emery \& Clayton, 2009). Corvids present an excellent opportunity to examine sociocognitive abilities, as they have natural variation in their caching behavior and socioecology, both argued to influence cache protection strategies (Dally, Emery, \& Clayton, 2006a). For instance, Clark's nutcrackers (Nucifraga columbiana) make thousands of caches in the autumn and rely on these food stores almost exclusively over the subsequent winter and spring, whereas jackdaws (Corvus monedula) do not cache at all (de Kort \& Clayton, 2006). California scrub jays (Aphelocoma californica) are semisocial and live in small groups, whereas Eurasian jays (Garrulus glandarius) are territorial (Emery \& Clayton, 2009). Joining these two facets, caching and sociality, through the investigation of cache protection strategies, has provided an insight into whether the socioecological demands of a particular species influence its cache protection strategies (Clayton, Dally, \& Emery, 2007; Dally, Emery, \& Clayton, 2006a).

During a typical experimental caching paradigm, an individual bird is provided with a source of food that can be cached and several locations suitable for caching - in many instances, these have been open areas (e.g., Bednekoff \& Balda, 1996; Bugnyar \& Heinrich, 2006; Shaw \& Clayton, 2012) or small plastic trays (e.g., Clary \& Kelly, 2011; Dally, Emery, \& Clayton, 2004, 2006b; Emery \& Clayton, 2001; Emery, Dally, \& Clayton, 2004). The caching individual is permitted to consume and cache the food. This caching phase is conducted with the bird alone, or in the presence of another individual-typically a conspecific or a heterospecific. If another bird is present, this observer is often allowed to pilfer the caches either immediately or at a later time. A central element to this paradigm is that the cacher has an opportunity to witness the fate of its caches; if it caches in private, the caches remain intact, whereas if it caches in the presence of another individual, some proportion of its caches may be pilfered. As this sequence of events is often repeated, the cacher has an opportunity to learn about the pilfering risk associated with the presence of an observer and modify its caching behavior over time, such as engaging in cache protection strategies to reduce the risk of future cache loss (e.g., relocating caches to less risky sites, caching behind a barrier or in shady locations, reducing possible indirect cues associated with a cache; Dally, Emery, \& Clayton, 2004, 2005, 2006b; Legg \& Clayton, 2014; Shaw \& Clayton, 2013; Tornick, Rushia, \& Gibson, 2016). Researchers use this procedure to evaluate whether sociality influences the type of cache protection strategies species display. For instance, in comparison to when caching alone, relatively less social Clark's nutcrackers reduce the number of caches made (Clary \& Kelly, 2011), semisocial California scrub jays recache more (Emery et al., 2004), and highly social pinyon jays preferentially allocate their caches in safe locations (Vernouillet, 2020). Hence, the different cache protection strategies may be a reflection of the social environment.

The social environment provides many cues that may be important to the initiation of cache protections strategies. Mountain chickadees (Poecile gambeli) have been shown to engage in cache protection strategies by hiding food in locations out of view, when observed by a conspecific or a known pilfering heterospecific (red-breasted nuthatch, Isitta canadensis), but continued to cache in view of known non-pilfering heterospecific (dark-eyed junco, Junco hyemalis; Pravosudov, 2008). Pinyon jays are also reported to engage in cache protection strategies when observed by a conspecific or a known pilfering heterospecific (Clark's nutcracker), caching preferentially in safer locations. Interestingly, Clark's nutcrackers likewise engage in cache protection strategies, in the form of cache consumption and reducing the number of caches made, when viewed by a conspecific, but did not show such behavior when observed by a known pilfering heterospecific (pinyon jay). Vernouillet (2020) argued these species differences in cache protection strategies may be attributable to the social environment.

The relative social status (dominant or subordinate) within a group has also been shown to influence a caching bird's behavior when observed. When caching in the presence of a dominant conspecific, Eurasian jays respond by suppressing caching behavior, followed by placing caches in less visible locations. In contrast, when caching in the presence of a subordinate conspecific, Eurasian jays increased the amount of caching as well as recached items (Shaw \& Clayton, 2012). Although fewer studies have examined whether the individual identity of the observer is encoded, some food-storing species have been shown capable of identifying group members during food competition scenarios (Bugnyar, 2011; Paz-y-Mino, Bond, Kamil, \& Balda, 2004). The ability to discriminate among group members may be beneficial in food-caching situations, particularly by species that live in large social groups (Yorzinski, 2017) or by species that may face competition at high-quality or ephemeral food sites (Bugnyar \& Heinrich, 2006).

Importantly, concluding that food-storing birds may be capable of using aspects of the social environment to inform caching behavior requires that other non-social cues, or "killjoy explanations," be carefully considered (Shettleworth, 2010). Clary and Kelly (2011) evaluated whether Clark's nutcrackers would engage in similar cache protection strategies when cache loss was associated with a conspecific or an inanimate human-made object. The nutcrackers' behavior supported that the object was not responded to as a potential pilfering threat, as they continued to cache at a rate similar to when in private. Comparable results were also reported for pinyon jays (and Clark's nutcrackers) by Vernouillet (2020). However, for 
both of these studies, the human-made items were artificial, which may have contributed to the dismissal of these objects as irrelevant or inconsequential. In contrast, taxidermy models provide more naturalistic qualities and are often used to investigate animals' responses to predator risk (e.g., Curio, Ernst, \& Vieth, 1978; Maziarz, Piggott, \& Burgess, 2018). As such, using a more naturalistic object, such as a taxidermy bird, may be a better control to assess whether birds adjust their caching behavior based on non-social cues, such as cache loss, or social cues, such as the observer's behavior.

Using the pinyon jay, the current study investigated two central issues: (1) whether pinyon jays can discriminate between a pilfering conspecific and a non-pilfering conspecific, and (2) whether a naturalistic object would be responded to as a potential pilferer. Pinyon jays are a highly social corvid species that live in large flocks with high fission-fusion dynamics (Clayton \& Emery, 2008; Marzluff \& Balda, 1992). They are also a long-term food-storing species that caches thousands of pine seeds in the autumn as a main source of nourishment throughout the winter and spring (Vander Wall, 1990). These combined factors make them an ideal candidate to explore whether corvids adjust their caching behavior in response to the social context.

To evaluate whether pinyon jays modify their caching behavior in response to the social context, we allowed individuals to cache in the presence of an individual that always pilfered their caches, or an individual that never pilfered their caches. This procedure permitted us to evaluate whether pinyon jays are able to differentiate between individuals. Based on previous research supporting individual recognition in corvids (e.g., Kondo, Izawa, \& Watanabe, 2012; Zandberg, Jolles, Boogert, \& Thornton, 2014), we hypothesized that cachers would show cache protection strategies in the presence of the pilfering individual, but would not show these strategies when in the presence of the non-pilfering individual (caching behavior in the latter situation would not differ from when in private). To evaluate whether pinyon jays would respond to a naturalistic object as if it were a potential pilferer, we allowed individuals to cache in the presence of a heterospecific taxidermy avian mount. Importantly, the presence of this mount was correlated with cache loss. Together, these conditions allowed us to examine whether pinyon jays are able to discriminate between a pilfering and non-pilfering individual, and whether a naturalistic object, associated with cache loss, would be responded to as a potential pilferer.

\section{Methods}

\section{Subjects}

Wild-caught adult pinyon jays served as caching birds (herein referred to as cachers; $n=6$, three females) and as observing birds (herein referred to as observers; $n=4$, two females). All individuals were captured as adults from populations around Flagstaff (Arizona, USA) and were in captivity for approximately 10 years prior to the study. All birds had previously participated in both caching (Vernouillet, 2020) and noncaching experiments (e.g., Vernouillet \& Kelly, 2020).

Birds were housed in the animal facilities of the Department of Psychology at the University of Manitoba, in a colony room maintained at $22^{\circ} \mathrm{C}$ with a $12: 12$ light:dark cycle, with light onset at 0700 (CST). Birds were held in individual cages (width $\times$ length $\times$ height: $51 \times 51 \times 72 \mathrm{~cm}$ ) with multiple perches and had ad libitum access to water and grit. When not experiencing the experimental food restriction procedures (see below), their diet consisted of a mixture of parrot pellets, turkey starter, peanuts, dried mealworms, and sunflower seeds, with added oyster shell powder and vitamin powder supplement Prime ${ }^{\circledR}$. Birds were monitored and weighed daily to ensure a healthy weight during the study.

All applicable international, national, and/or institutional guidelines for the care and use of animals were followed. Our research protocol was approved by University of Manitoba's Animal Care Committee (\#F2014-037) and complied with the guidelines set by the Canadian Council on Animal Care.

\section{Apparatus}

The study was conducted in a separate procedural room. Individual birds were tested in a cage (width $\times$ length $\times$ height: $123.5 \times 63.5 \times 74.5 \mathrm{~cm})$ that was surrounded by white shower curtains. The cage was divided into two equally sized compartments, each of which contained a perch. One compartment served as the "caching compartment," whereas the other served as the "observing compartment." The two compartments were separated by a transparent acrylic divider (see Fig. 1).

Within the caching compartment, cachers were given two ice-cube trays (width $\times$ length: $11 \times 49.5 \mathrm{~cm}$ ), each containing 26 individual wells filled with sand using a $2 \times 13$ array, attached to a wooden board. To make each tray visually distinct, three unique MegaBlocks ${ }^{\mathrm{TM}}$ structures of the same color, but with different block arrangements, were attached to the edge of the wooden board of each tray. These structures were kept constant throughout the duration of the study, with each bird receiving the same pair of distinct trays. One tray (herein referred to as the pilfered tray) was placed along the acrylic divider separating the two compartments, whereas the other (herein referred to as the safe tray) was positioned along the opposite wall of the caching compartment, parallel to the first tray. A food dish containing 50 pine seeds was placed in the caching compartment, beside the cage door and between the two trays. All trials were recorded using the motion tracking software BiObserve ${ }^{\circledR}$ operating on a Red Barn ${ }^{\circledR}$ computer 


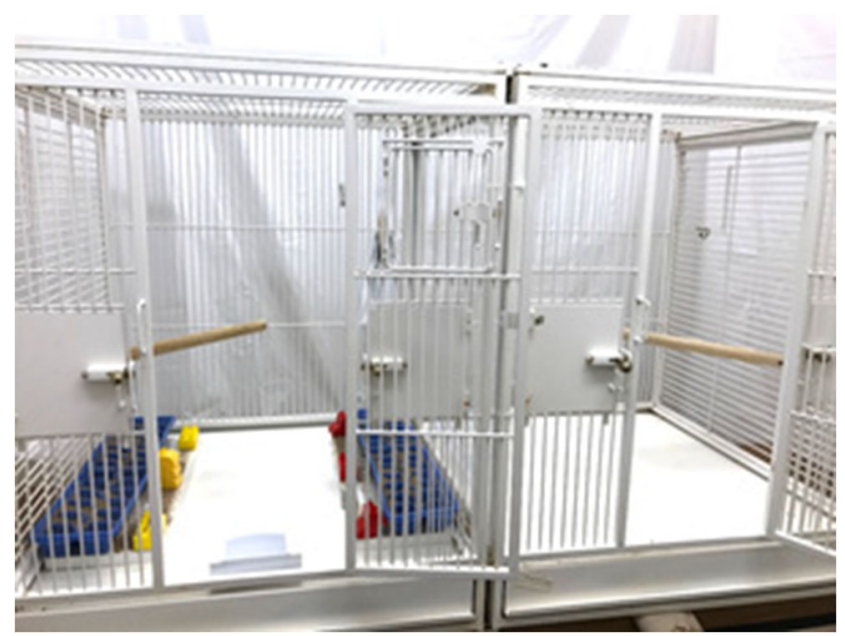

Fig. 1 Experimental setup during the caching phase. The two visually distinct caching trays, a pilfered tray (along the divider separating the two compartments) and a safe tray (on the opposite side) were placed in the caching compartment (left side). The adjoining observing compartment (right side) could contain either an inanimate heterospecific, a pilfering conspecific, a non-pilfering conspecific, or remain empty (as shown here)

(Windows 7), which was connected to an EverFocus ${ }^{\circledR} 1 / 3$-in. color digital camera positioned beside the experimental cage, behind the white curtains, to be minimally visible to the birds.

\section{Experimental procedures}

The procedures were modified from Clary and Kelly (2011) and were the same as those used by Vernouillet (2020). Generally, each cacher experienced 2 consecutive days of testing per week. Cachers were food restricted $24 \mathrm{hr}$ before the start of the first day (of every week) to motivate the birds to cache. During the first day, an individual cacher experienced three phases: caching, pilfering, and recaching, whereas during the second day, an individual cacher experienced only one phase, the retrieving phase. The 45-min caching phase was immediately followed by the 3-min pilfering phase. Cachers were then given a 1-hour break followed by the 5-min recaching phase. After completion of the recaching phase, they were returned to their home cage in the colony room, and provided with one teaspoon of diet mixture to ensure a healthy weight during the experiment. During the second day, the cacher experienced the retrieving phase, which could consist of one or more trials as necessary, to allow the cacher an opportunity to retrieve all of the caches it made the previous day.

\section{Experimental phases}

Caching phase At the start of the caching phase, the transparent divider separating the two compartments was covered by an opaque white corrugated plastic divider, and the observing compartment was set up as per the condition to be completed during the session (see Conditions below-i.e., it would be empty, contain a taxidermy mount of an avian heterospecific, or contain another pinyon jay; see Fig. 2). Once the cacher was placed inside the caching compartment, the opaque cover was removed (but the transparent divider remained in place) to permit the cacher visual access (but not physical access) to the observing compartment. During the caching phase, the cacher was able to consume or cache pine seeds in the two trays. At the end of the caching phase, the two caching trays were removed from the caching compartment to allow the experimenter an opportunity to record the number of pine seeds cached in each tray. Although the cacher remained in the caching compartment, it could not see the actions of the experimenter. The wells were carefully searched by the experimenter, and pine seed numbers and locations were recorded. All pine seeds were placed back in their original locations and the sand redistributed such that the tray looked as "untouched" as possible.

Pilfering phase Immediately after the caches in the trays were counted, a 3-min pilfering session was started, during which the pilfered tray was placed in the observing compartment of the cage, flush against the divider, in the same orientation as during the caching phase. During conditions with an observing bird present in the observing compartment (see Fig. 2c-d), the pilfered tray was accessible to the observing bird. The safe tray was placed on a stool outside of the cage, inaccessible but within the view of both the caching and observing birds. Upon completion of the pilfering phase, both birds were returned to the colony room.

Recaching phase Approximately 1 hour after the pilfering phase, the cacher was transported from the colony room and placed in the caching compartment of the experimental cage, and permitted access to both trays while alone (the observing compartment was empty). This recaching phase provided an opportunity for the cacher to consume the pine seeds it had previously cached, or to recache them. This procedure allowed individuals to interact with their caches after witnessing the pilfering event, while still being satiated from the caching phase, and to differentiate birds' cache protection strategies from behaviors motivated by hunger. After $5 \mathrm{~min}$, the cacher was again returned to the colony room and provided with one teaspoon of diet mix. This supplemental feeding was to ensure that the weight of the bird remained in the healthy range, while keeping the bird motivated to retrieve its caches the following day (Clary \& Kelly, 2011; Vernouillet, 2020).

Retrieving phase The following day ( $24 \mathrm{hr}$ after completing the caching phase), the cacher was allowed to retrieve the remaining caches during one or multiple 45 -min retrieving trial(s), while alone (for all conditions described below). At 
a)
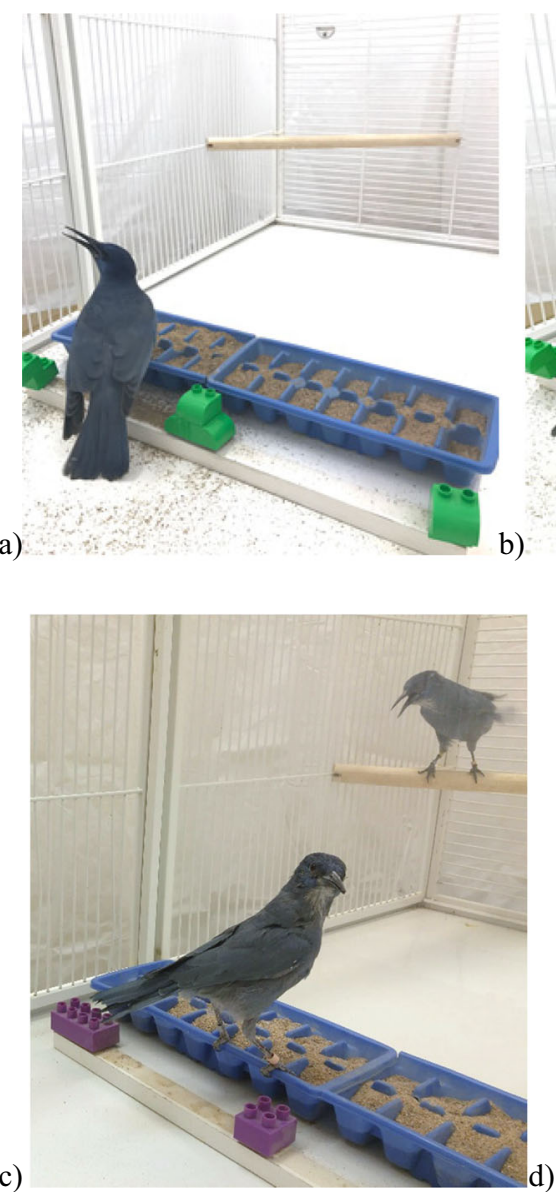

Fig. 2 Pictorial representations of the experimental conditions during the caching phase. The caching compartment contained the cacher (nearest bird), and the observing compartment remained empty, contained an

the end of each retrieving trial, the number and location of the pine seeds cached were noted once again, together with any recaching occurrences. Additional retrieving trials were provided every 3 hours and, if necessary, on the following day, until the cacher recovered the entirety of its caches.

\section{Conditions}

Each cacher was presented with a first block consisting of three sessions (three weeks) of the alone condition to establish a baseline for an individual's caching and retrieving rates (herein referred to as baseline). Next, each cacher was presented with five blocks (i.e., blocks two, three, four, five, and six) of four conditions (alone, inanimate heterospecific, pilfering conspecific, and non-pilfering conspecific), with each condition randomly selected and not repeated within the same block. Each condition refers to what (if anything) was present in the observing compartment during the caching and pilfering phases. During both of the conspecific conditions, the observer-cacher pair was consistent throughout the study. Observers did not participate as cachers to exclude potential
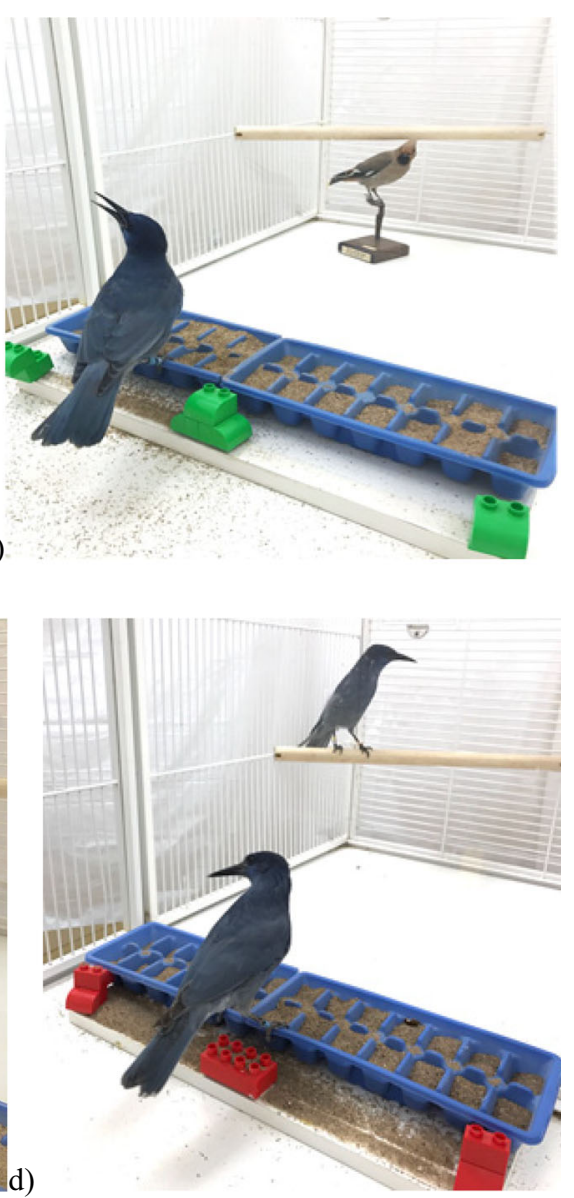

inanimate heterospecific, or contained another pinyon jay depending on the condition: a alone, $\mathbf{b}$ inanimate heterospecific, $\mathbf{c}$ pilfering conspecific, and $\mathbf{d}$ non-pilfering conspecific

effects of pilfering experience on their caching behavior (Emery \& Clayton, 2001).

Baseline/alone During the caching phase, the cacher cached in private (i.e., the observing compartment was empty; see Fig. 2a). During the pilfering phase, the pilfered tray was put in the observing compartment for three minutes, and the caches made in the tray remained intact. Both trays were then returned to the caching compartment during the recaching phase. The retrieving phase(s) was/were conducted the following day(s). The baseline condition (i.e., block one) served to assess the baseline caching behavior of individuals, and was used to assess whether exposure to the experimental conditions changed the caching behavior of individuals. The alone condition was conducted in an identical manner, but it occurred interspersed with the other experimental conditions.

Inanimate heterospecific During the caching phase, an inanimate taxidermy mount of a bohemian waxwing (Bombycilla garrula) was placed under the perch in the observing 
compartment facing the caching compartment (see Fig. 2b). During the conspecific conditions, the observers spent most of their time in this location (A.V., pers. obs.); therefore, the bird mount was likewise placed under the perch. During the pilfering phase, the pilfered tray was placed in the observing compartment with the bird mount for 3 minutes, whereas the safe tray was placed on a stool outside of the cage, remaining visible to the cacher. After the pilfering phase (but before the recaching phase) and out of sight of the cacher, the experimenter removed pine seeds from the pilfered tray, such that all areas of the tray were pilfered equally. Pilfering rate was kept consistent across individuals by removing $33 \%$ of pine seeds cached during the second, third, fifth, and sixth blocks, and $50 \%$ of pine seeds cached during the fourth block, to resemble variation in pilfering rates as would be experienced naturally (Vander Wall \& Jenkins, 2003). Both trays were then given to the cacher during the recaching phase. The retrieving phase(s) was/were conducted the following day(s). The inanimate heterospecific condition served as a control condition, to determine whether pinyon jays modify their caching behavior in response to caches loss, independent of whether the observer approached the tray or the caches. Previous studies have used an artificial humanmade object, our use of a bird mount allowed for a more naturalistic stimulus.

Pilfering conspecific During the caching phase, an observing pinyon jay was placed in the observing compartment (see Fig. 2c). During the pilfering phase, the pilfered tray was placed in the adjoining compartment with the observer, who was given 3 minutes to access the tray, and permitted to remove cached pine seeds, in view of the cacher. Meanwhile, the safe tray was placed on an inaccessible stool outside of the cage, but visible to both birds. At the end of the pilfering phase, and out of the birds' view, the experimenter adjusted the pilfering rate so that it was the same as what was experienced during the inanimate heterospecific condition. Both trays were given back to the cacher during the recaching phase. The retrieving phase (s) was/were conducted the following day(s).

Non-pilfering conspecific This condition was conducted as during the pilfering conspecific condition (see Fig. 2d), with the exception that the experimenter removed all pine seeds cached from the pilfered tray at the end of the caching phase, out of the birds' view, and before the pilfering phase. Since no pine seeds were available to pilfer, even if the non-pilfering bird interacted with the tray, the cacher never observed it remove any cached pine seeds during the pilfering phase. Following the pilfering phase, the experimenter replaced all caches in the pilfered tray so that the tray was in the same state as at the end of the caching session. Hence, no caches were pilfered during this condition. Both trays were given back to the cacher during the recaching phase. The retrieving phase(s) was/were conducted the following day(s).

\section{Analyses}

Dependent variables During the caching phase, we examined the number of seeds eaten and the number of seeds cached. During the recaching phase, we examined the number of seeds eaten and the number of seeds recached. Specifically, the precise well location of each seed was recorded for each tray after caching. After the recaching phase, if a seed remained in the same well location, it was considered intact, and if the seed was missing from the well, it was considered either recached or eaten. For these latter two cases, if an extra seed was found in a different well of the same tray or in the opposite tray, the seed was considered recached, whereas if the seed was completely missing from the trays and the cage, it was considered eaten. The location of cached and recached seeds (i.e., pilfered vs. safe trays) was also examined to determine if cachers associated the pilfering theft specifically with the pilfered tray, but not the safe tray.

To determine whether cachers modified their caching behaviors, the total number of pine seeds eaten or cached/ recached per trial, and the tray identity (safe or pilfered), was compared across all conditions. To evaluate whether the caching bird's behavior remained similar throughout the study, when caching alone, we compared the caching phases of the baseline and the alone conditions. If no differences were found, we then used the alone condition as a control to evaluate behavioral changes during the pilfering conspecific, non-pilfering conspecific, and inanimate heterospecific conditions. If the behavior of the cacher differed between the baseline and the alone conditions, we compared all the experimental conditions with the baseline condition. To examine whether the observer's interaction with the pilfered tray, during the pilfering phase, affected caching behavior, we compared the pilfering conspecific and non-pilfering conspecific with the inanimate heterospecific conditions. Finally, to establish whether cachers associated the reduction of caches in the pilfered tray (i.e., pilfering rate) to a pilfering threat, we compared the pilfering conspecific and the inanimate heterospecific conditions with the non-pilfering conspecific condition (see Table 1 for a summary).

Statistical analyses We used a generalised linear mixed model (GLMM) approach for our analyses, with the number of seeds eaten and the number of seeds cached during the caching phase and the number of seeds eaten and the number of recached seeds during the recaching phase as dependent variables. Condition (i.e., baseline, alone, inanimate heterospecific, pilfering conspecific, non-pilfering conspecific), block, and cacher's sex were included as fixed factors in our models. We performed separate analyses on the 
Table 1 Experimental manipulations during each condition

Conditions Presence Interaction with the Pilferage of pine seeds of an pilfered tray (during cached in the pilfered observer the pilfering phase) tray (after the pilfering phase)

\begin{tabular}{llll}
\hline Alone & $x$ & $x$ & $x$ \\
Object & $\checkmark$ & $x$ & $\checkmark$ \\
Non-pilfering & $\checkmark$ & $\checkmark$ & $x$ \\
Pilfering & $\checkmark$ & $\checkmark$ & $\checkmark$ \\
\hline
\end{tabular}

number of seeds cached in each tray to determine whether the cachers used the two trays differently. For these analyses, we included tray identity (pilfered vs. safe) as an additional fixed factor. For all models, identity of the cacher was included as a random factor to account for repeated measures taken on each individual. Residual plots indicated assumptions of normality were met. Analyses were conducted using R Version 3.3.2 with the lme4, qpcR, psych, and lsmeans packages (Bates, Maechler, Bolker, \& Walker, 2015; Lenth, 2016; Revelle, 2017; Spiess, 2018).

To assess the fit of each model, we used Akaike's information criterion (AIC). Models were considered equivalent when $\triangle A I C<2.0$. For each dependent variable, we considered the best model(s) explaining the variability of the data (i.e., the model with the lowest $A I C$ ). We obtained $p$ values for each fixed factor (i.e., tray, condition, block, sex, Block $\times$ Condition, Condition $\times$ Tray, Block $\times$ Tray, and Condition $\times$ Block $\times$ Tray) using likelihood ratio tests of the model with the fixed factor of interest against the model without it. Parameter estimation was achieved using residual maximum likelihood. Post hoc analyses were conducted using pairwise comparisons. The $p$ values of post hoc analyses were adjusted using the Tukey method to consider multiple comparisons (Lenth, 2016). Alpha was set at 0.05 for all statistical analyses.

\section{Results}

\section{Caching phase}

Total number of seeds eaten There were no significant differences in the number of seeds eaten during the caching phase among the conditions $(M \pm S E: 14.1 \pm 0.9), \chi^{2}(4)=1.684, p=$ .794 (see Table 2). No other fixed factors examined in our analyses explained the number of seeds eaten during the caching phase (see Table 2).

Overall number of seeds cached The best model explaining the overall number of seeds cached included conditions as the
Table 2 Models explaining the number of pine seeds eaten by pinyon jays during the caching phase

\begin{tabular}{lllllll}
\hline Model & AIC & $\Delta$ AIC & $d f$ & Weight & Deviance & $p$ value \\
\hline Null & 745.2 & 0.0 & 3 & 0.67 & 739.2 & \\
Sex & 747.0 & 1.8 & 4 & 0.27 & 739.0 & .684 \\
Block & 751.1 & 5.9 & 8 & 0.03 & 735.1 & .534 \\
Condition & 751.5 & 6.3 & 7 & 0.03 & 737.5 & .794 \\
Condition $\times$ Block & 773.2 & 28.0 & 23 & 0.00 & 727.2 & .918 \\
\hline
\end{tabular}

fixed factor, $\chi^{2}(4)=10.664, p=.031$ (see Fig. 3, Table 3). There were no differences in the overall number of seeds cached between the baseline and the alone conditions $(M \pm$ $S E$ : baseline: $20.2 \pm 2.6$, alone: $24.3 \pm 1.7$ ). The lack of difference between the baseline and the alone condition supports the use of the alone condition as a control for further comparisons. Once the baseline condition was removed, there were no differences in the overall number of seeds cached among conditions ( $M \pm S E$ : inanimate heterospecific: $24.9 \pm 2.0$, pilfering conspecific: $22.7 \pm 1.5$, non-pilfering conspecific: $22.4 \pm 1.9), \chi^{2}(3)=5.789, p=.122$. No other fixed factors explained the overall number of seeds cached (see Table 3 ).

Number of seeds cached per tray The number of pine seeds cached in each tray was best explained by condition, $\chi^{2}(9)=$ $158.28, p<.001$ (see Fig. 4, Table 3). During baseline condition, birds cached a similar amount of pine seeds in each tray, $t(270)=-1.090, p=.277$, whereas for all experimental conditions, cachers cached more seeds in the safe tray in comparison with the pilfered tray, alone: $t(270)=-4.082, p<.001$; inanimate heterospecific: $t(270)=-5.957, p<.001$; pilfering conspecific: $t(270)=-8.809, p<.001 ;$ non-pilfering conspecific: $t(270)=-8.837, p<.001$ (see Fig. 4).

The number of pine seeds cached in the safe tray during the baseline condition compared with alone was not significantly different $(M \pm S E$ : baseline: $11.0 \pm 2.2$, alone: $14.8 \pm 1.3)$, $t(270)=2.516, p=.090$. Birds cached a similar amount of pine seeds in the safe tray during the inanimate heterospecific $(M \pm S E: 16.3 \pm 1.3), t(270)=-1.197, p=0.753$, the nonpilfering conspecific (number of pine seeds cached $\pm S E$ : 16.9 $\pm 1.5), t(270)=-1.651, p=.466$, and the pilfering conspecific conditions (number of pine seeds cached $\pm S E$ : $17.1 \pm 1.4$ ), $t(270)=-1.770, p=.393$, compared with the alone condition. Similarly, there were no statistical differences in the number of pine seeds cached in the safe tray between the inanimate heterospecific condition and the non-pilfering conspecific condition, $t(270)=0.454, p=.991$, between the inanimate heterospecific condition and the pilfering conspecific condition, $t(270)=0.574, p=.979$, nor between the non-pilfering conspecific condition and the pilfering conspecific condition, $t(270)=0.120, p=1.000$. 
Table 3 Models explaining the number of pine seeds cached by pinyon jays during the caching phase

\begin{tabular}{|c|c|c|c|c|c|c|}
\hline Model & $A I C$ & $\triangle A I C$ & $d f$ & Weight & Deviance & $p$ value \\
\hline \multicolumn{7}{|c|}{ Overall number of pine seeds cached } \\
\hline Condition & 891.6 & 0.0 & 7 & 0.57 & 877.6 & $.031 *$ \\
\hline Sex & 893.6 & 2.0 & 4 & 0.21 & 885.6 & .105 \\
\hline Null & 894.3 & 2.7 & 3 & 0.15 & 888.3 & \\
\hline Block & 895.9 & 4.3 & 8 & 0.07 & 879.9 & .139 \\
\hline Condition $\times$ Block & 913.7 & 22.1 & 23 & 0.00 & 867.7 & .421 \\
\hline \multicolumn{7}{|c|}{ Number of pine seeds cached per tray } \\
\hline Tray $\times$ Condition & $1,721.1$ & 0.0 & 12 & 1.00 & $1,697.1$ & $<.001 * *$ \\
\hline Tray & $1,740.9$ & 19.8 & 4 & 0.00 & $1,732.9$ & $<.001 * *$ \\
\hline Tray $\times$ Block & $1,741.5$ & 20.4 & 14 & 0.00 & $1,713.5$ & $<.001 * *$ \\
\hline Tray $\times$ Condition $\times$ Block & $1,771.3$ & 50.2 & 20 & 0.00 & $1,683.3$ & $<.001 * *$ \\
\hline Null & $1,861.4$ & 140.3 & 3 & 0.00 & $1,855.4$ & \\
\hline
\end{tabular}

$* p<.05, * * p<.001$

The number of pines seeds cached in the pilfered tray during the baseline condition compared with the alone condition was not significantly different $(M \pm S E$ : baseline: $9.2 \pm 1.5$, alone: $9.5 \pm 1.0), t(270)=0.199, p=1.000$. The birds, however, cached significantly fewer pine seeds in the pilfered tray during the non-pilfering conspecific condition $(M \pm S E: 5.4 \pm$ $0.8), t(270)=3.103, p=.018$, and the pilfering conspecific condition $(M \pm S E: 5.6 \pm 0.8), t(270)=2.956, p=.028$, compared with the alone condition. The number of pine seeds cached in the pilfered tray did not differ between the inanimate heterospecific condition $(M \pm S E$ : $8.6 \pm 1.0)$ and the alone condition, $t(270)=0.678, p=.961$. Similarly, there were no differences in the number of pine seeds cached in the pilfered tray between the inanimate heterospecific condition and the non-pilfering conspecific condition, $t(270)=$ $-2.425, p=.112$, between the inanimate heterospecific

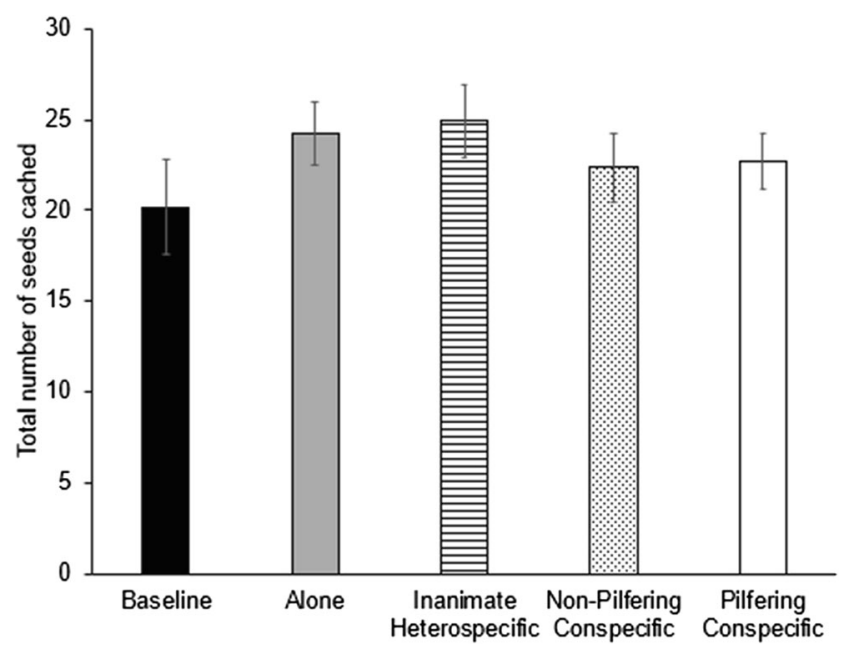

Fig. 3 Total number of pine seeds cached $( \pm S E)$ by pinyon jays during the caching phase during the baseline, alone, inanimate heterospecific, non-pilfering conspecific, and pilfering conspecific conditions condition and the pilfering conspecific condition, $t(270)=$ $-2.278, p=.155$, nor between the non-pilfering conspecific condition and the pilfering conspecific condition, $t(270)=$ $0.147, p=1.000$. No other fixed factors examined in our analyses explained the number of seeds cached per tray during the caching phase (see Table 3).

\section{Recaching phase}

Total number of seeds eaten There were no significant differences in the number of pine seeds eaten during the recaching phase among the conditions $(M \pm S E$ : $2.2 \pm 0.3), \chi^{2}(4)=$ $0.673, p=.955$ (see Table 4). No other fixed factors examined in our analyses explained the number of seeds eaten during the recaching phase.

Overall number of recached seeds The overall number of recached seeds was best explained by block, $\chi^{2}(5)=19.170$, $p=.002$ (see Table 5). Birds showed an increase in the overall number of recached seeds across blocks: first block $(M \pm S E$ : $3.7 \pm 1.0)$ and the third $(M \pm S E: 6.6 \pm 0.9), t(132)=2.894, p=$ $.050)$, fourth $(M \pm S E: 7.4 \pm 1.1), t(132)=3.660, p=.005$, and fifth blocks $(M \pm S E: 7.7 \pm 1.2), t(132)=3.919, p=.002$, and tended to increase during the last block $(M \pm S E$ : $6.6 \pm 1.0$, $t(132)=2.842, p=0.057)$. No other fixed factors used in our models explained variation of overall number of seeds recached (see Table 5).

Number of recached seeds per tray The number of recached pine seeds in each tray was best explained by block, $\chi^{2}(11)=$ 29.498, $p=.002$ (see Table 5). During all six blocks, birds recached a similar amount of pine seeds in each tray $(M \pm S E$ : first block: safe tray: $2.0 \pm 0.7$, pilfered tray: $1.7 \pm 0.5), t(270)$ $=-0.370, p=.712 ;$ (second block: safe tray: $2.8 \pm 0.7$, pilfered 


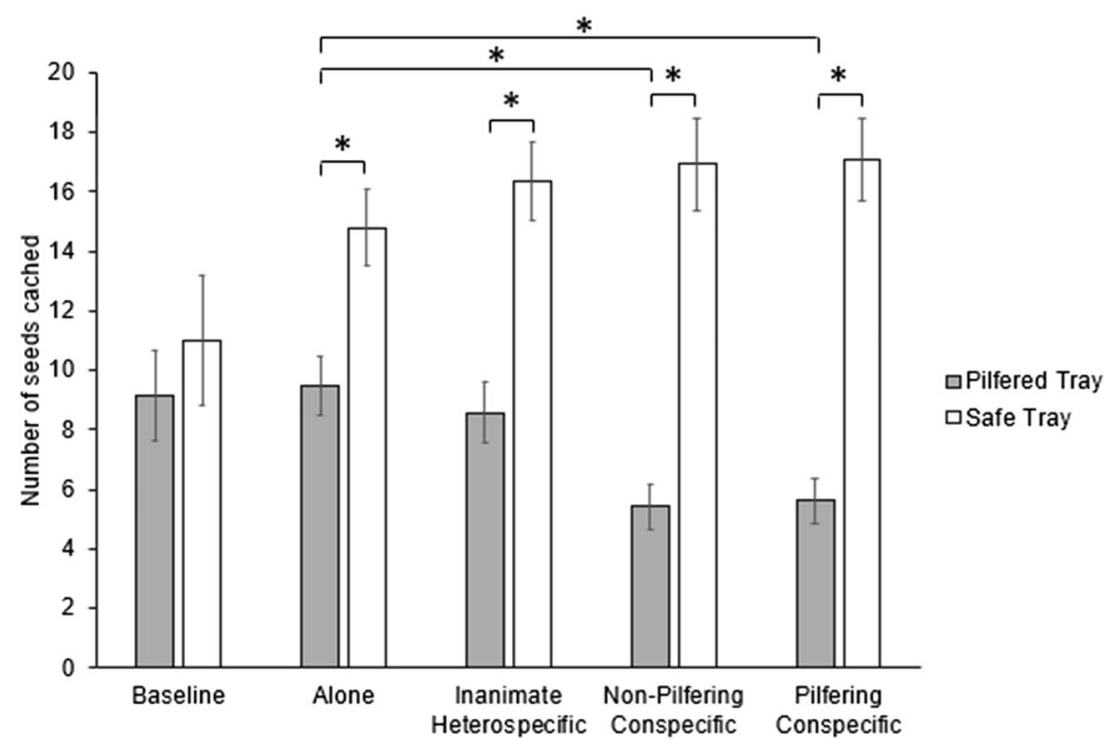

Fig. 4 Number of pine seeds cached $( \pm S E)$ in the safe and in the pilfered trays by caching pinyon jays in each experimental condition during the caching phase $(p<.001) * p<.05$

tray: $1.8 \pm 0.4), t(270)=-1.474, p=.142 ;($ third block: safe tray: $3.8 \pm 0.6$, pilfered tray: $2.9 \pm 0.5), t(270)=-1.330, p=$ .185; (fourth block: safe tray: $3.8 \pm 0.6$, pilfered tray: $3.6 \pm$ $0.7), t(270)=-0.433, p=.666$; (fifth block: safe tray: $3.6 \pm$ 0.7 , pilfered tray: $4.0 \pm 0.8), t(270)=0.641, p=.522 ;($ sixth block: safe tray: $3.2 \pm 0.6$, pilfered tray: $3.4 \pm 0.6), t(270)=$ $0.192, p=.848$. The number of recached pine seeds in the safe tray did not significantly differ between blocks.

The birds increased the number of recached pine seeds in the pilfered tray during the fifth block in comparison to the first block, $t(270)=3.303, p=.014$, and the second block, $t(270)=0.129, p=.009$. No other comparisons were significantly different. No other fixed factors used in our models explained the number of recached seeds per tray (see Table 5).

\section{Discussion}

The current study investigated whether pinyon jays adjust their caching behavior in response to the social context. During the caching phase, individuals cached or ate a similar

Table 4 Models explaining the number of pine seeds eaten by pinyon jays during the recaching phase

\begin{tabular}{lllllll}
\hline Model & AIC & $\Delta$ AIC & $d f$ & Weight & Deviance & $p$ value \\
\hline Null & 616.9 & 0.0 & 3 & 0.55 & 610.9 & \\
Sex & 617.5 & 0.6 & 4 & 0.41 & 609.5 & .236 \\
Block & 623.4 & 6.5 & 8 & 0.02 & 607.4 & .618 \\
Condition & 624.3 & 7.4 & 7 & 0.01 & 610.3 & .955 \\
Condition $\times$ Block & 643.4 & 26.5 & 23 & 0.00 & 597.4 & .855 \\
\hline
\end{tabular}

number of pine seeds regardless of whether they were observed by a conspecific, an inanimate heterospecific, or when they were caching alone. However, the specific location where the caching bird chose to place its caches, in a safe tray or in a tray that could be pilfered from, was affected by the social context. Specifically, when being observed by a conspecific, birds cached fewer seeds in the pilfered tray compared with when they cached alone. This result supports that the cacher interpreted the presence of an observing pinyon jay as a threat, regardless of its experience with the observer pilfering its caches. When observed by an inanimate heterospecific, the birds made a similar number of caches to the pilfered tray as when caching alone. This result seems to support that the birds did not interpret the inanimate heterospecific as a threat. Yet, when comparing across the three observed conditions, the pinyon jays made fewer caches to the pilfered tray when observed by the conspecifics compared with the inanimate heterospecific, but again this was not significant. Thus, these results show that birds placed the least caches in the pilfered tray when observed, compared with when alone, but the caching behavior with the inanimate heterospecific was intermediary (not statistically different than the alone condition, but also not different from either of the conspecific conditions). During the recaching phase, individuals recached more of their seeds with successive experience, but this behavior was similar across all caching conditions. Thus, overall, we found that pinyon jays showed cache protection behaviors, allocating a greater number of caches to the safe tray compared with the pilfered tray, when being observed making their caches. There were no differences in their caching behavior when pinyon jays were in the presence of a conspecific associated with cache pilferage and one that was not. They also showed an intermediate response to the inanimate heterospecific, with 
Table 5 Models explaining the number of recached pine seeds by pinyon jays during the recaching phase

\begin{tabular}{|c|c|c|c|c|c|c|}
\hline Model & $A I C$ & $\triangle A I C$ & $d f$ & Weight & Deviance & $p$ value \\
\hline \multicolumn{7}{|c|}{ Overall number of recached pine seeds } \\
\hline Block & 751.7 & 0.0 & 8 & 0.75 & 735.7 & $.002 *$ \\
\hline Conditions & 754.0 & 2.3 & 7 & 0.24 & 740.0 & $.005 *$ \\
\hline Null & 760.9 & 9.2 & 3 & 0.01 & 754.9 & \\
\hline Sex & 762.9 & 11.2 & 4 & 0.00 & 754.9 & .991 \\
\hline Condition $\times$ Block & 772.4 & 20.7 & 23 & 0.00 & 726.4 & .098 \\
\hline \multicolumn{7}{|c|}{ Number of recached pine seeds per tray } \\
\hline Tray $\times$ Block & $1,279.8$ & 0.0 & 14 & 0.77 & $1,251.8$ & $.002 *$ \\
\hline Tray $\times$ Condition & $1,282.5$ & 2.7 & 12 & 0.20 & $1,258.5$ & $.007 *$ \\
\hline Null & $1,287.3$ & 7.5 & 3 & 0.02 & $1,281.3$ & \\
\hline Tray & $1,288.1$ & 8.3 & 4 & 0.01 & $1,280.1$ & .282 \\
\hline Tray $\times$ Condition $\times$ Block & $1,306.3$ & 26.5 & 44 & 0.00 & $1,218.3$ & $.015 *$ \\
\hline
\end{tabular}

$* p<.05, * * p<.001$

caching behavior not differing from either when caching alone or in the presence of conspecifics (this result should be interpreted cautiously due to the possibility of small sample sizes limiting statistical power).

\section{Caching behavior and sociality}

Results from our current study provide further support that food-storing corvids show cache protections strategies, but the nature of these strategies are species specific (e.g., Clary \& Kelly, 2011; Emery et al., 2004). In particular, our previous research has shown that Clark's nutcrackers, a relatively less social corvid, responded to a cache threat by consuming previously made caches (Clary \& Kelly, 2011) or reducing the number of caches (Vernouillet, 2020), whereas pinyon jays, a highly social corvid, preferentially allocated caches from risky locations to safe ones (Vernouillet, 2020). Vernouillet (2020) further showed that pinyon jays engaged in this cache protection behavior when observed by either a conspecific or by a heterospecific (a Clark's nutcracker). The different strategies used by nutcrackers and pinyon jays, as well as California scrub jays and Eurasian jays (e.g., Emery et al., 2004; Shaw \& Clayton, 2012, respectively) may be due to the pressures of their social environment. The territorial nutcracker may have ample opportunity to cache in private. Therefore, if a cache is potentially compromised by the presence of an observer, a nutcracker may either simply consume the cache or reduce its caching rate and make a new cache at a more opportune time. However, such occasions to cache in private may not be as plentiful for the highly social pinyon jay, which live in socially complex groups composed of hundreds of individuals (Marzluff \& Balda, 1992). During the fall, pinyon jays make caching trips in flocks of up to 20 individuals (Marzluff \& Balda, 1992), which forage and cache in close proximity (within 5 square meters; Balda \& Bateman, 1971). Hence, caching items in safer locations when a potential pilferer is present may be a more viable solution than waiting for an infrequent opportunity to cache in private.

\section{Does it matter who is watching?}

Previous studies have examined whether birds respond to the mere presence of something in the adjoining cage. The idea being, if birds engage in cache protection strategies when an observer is not a cache threat, such as an inanimate object, then this behavior would more parsimoniously be explained by associative learning. The birds could learn that when there is anything present in the adjoining compartment, regardless of the identity, the caches may be pilfered. Clary and Kelly (2011) showed that for Clark's nutcrackers, this is not the case; likewise, Vernouillet (2020) replicated this initial finding with nutcrackers, and extended it to pinyon jays. For both species, an inanimate object was not treated as a threat, even when paired with cache reduction. However, these studies used an artificial human-made object. For our current study, we used a taxidermy model of a bohemian waxwing, a species that is sympatric with pinyon jays, but does not pilfer their caches. This manipulation, of presenting a naturalistic object, led to interesting results when compared with previous studies. We again found that when presented with a possible cache threat, pinyon jays reduced the number of caches placed in the pilfered tray when being observed by live conspecifics, compared with when caching alone. However, they showed an intermediary response to the inanimate heterospecific, placing fewer caches in the pilfered tray compared with when alone, but more caches in the pilfered tray than when being observed by the live conspecifics - yet both of these comparisons failed to reach significance. Thus, pinyon jays do not interpret an 
inanimate human-made object as a threat (as supported by previous studies), but they also view an inanimate heterospecific differently from an animate conspecific. Our results suggest that pinyon jays may assess the presence of an observer, irrespective of its animacy (i.e., interaction with the pilfered tray during the pilfering phase), as a cache risk as long as it is sufficiently natural. Future studies will be necessary to evaluate which visual or motion-based properties of the observer provide important information when pinyon jays are assessing cache threat.

Food-storing birds have been shown to be capable of discriminating between observers that pose a cache threat and those that do not. Bugnyar, Schwab, Schloegl, Kotrschal, and Heinrich (2007) reported that ravens (Corvus corax) were able to discriminate between a human who stole a previously cached non-edible object (the pilferer) and one who did not (the onlooker). Ravens only modified their behavior when allowed to cache food (rather than an object) in the presence of the human observers. They were able to use knowledge learned with non-edible items and immediately transfer it when caching food items by starting to cache items more quickly and in locations hidden from the pilferer's view compared with when in the presence of the onlooker. Likewise, Pravosudov (2008) showed that when provided with an opportunity to cache in locations within direct view or hidden from view of a conspecific or a known pilfering heterospecific (red-breasted nuthatch), mountain chickadees preferred to cache in locations hidden from view. However, they did not show this location preference when caching under the observation of a known non-pilfering heterospecific (dark-eyed junco). Thus, as the mountain chickadees were not provided with direct experience (within the study) of a pilfering event, but differentiated between potential pilferers and non-pilferers, the authors argue that mountain chickadees might have evolved this ability. We have also previously reported that pinyon jays show cache protection strategies when observed by a pilfering conspecific or a heterospecific (Clark's nutcracker; Vernouillet, 2020). As with our current study, the strategy the pinyon jays displayed was to allocate caches from risky to safe locations, when observed by either species. Taken together these studies clearly support that food-storing birds modify their caching behavior when observed by potential heterospecific and conspecific pilferers.

During our current study, we found no differences in an individual's caching behavior when observed by a pilfering and by a non-pilfering individual, despite repeated exposures to both observers and the differential outcomes from those interactions. This finding indicates that pinyon jays responded to both individuals as a pilfering threat in this competitive context, irrespective of cache loss associated with one individual, but not the other. Yet pinyon jays have been shown to be cable of determining the social status of individuals by observing pairwise interactions during a food competition paradigm, supporting their ability to identify group members and to track relationships among them (Paz-y-Mino et al., 2004). When examining caching behavior, Bednekoff and Balda (1996) also found that although pinyon jays engage in caching behavior sooner when in the presence of subordinate individuals compared with when in the presence of dominant individuals, they did not show differences in other caching behaviors (e.g., latency to cache or seeds eaten before caching) with respect to observer status. Interestingly, the authors reported not observing clear cache protection strategies by the birds in their study (Experiment 1). As the caching and potential pilfering birds in their study interacted within the same space, a large open room, the opportunity to engage in cache protection behaviors may have been quite restricted or ineffective. Other foodstoring birds have been shown to modify their caching (and pilfering) behavior when in the presence of dominant or subordinate conspecifics (e.g., Bugnyar \& Heinrich, 2006; Shaw \& Clayton, 2012). For instance, the territorial Eurasian jays showed cache suppression and recaching of items to less conspicuous locations when observed by a dominant individual, whereas they made more caches and moved these caches more frequently when observed by a subordinate individual (Shaw $\&$ Clayton, 2012). Thus, the cues used when modifying caching behavior based on social status may be more general or conspicuous than those necessary for individual recognition.

Alternatively, it is possible that the caching pinyon jays in the current study were associating the presence or the behavior of the observers with cache risk. The pilfering and non-pilfering observers could approach the tray and search through the sand during the pilfering phase, even though the non-pilfering observer was not given an opportunity to pilfer caches. Possibly, the cache loss associated with the behaviors of the pilfering conspecific was also associated with similar behaviors displayed by the non-pilfering conspecific, or perhaps even the presence of a conspecific near the tray. This generalization might have resulted in the caching individual displaying similar cache protection strategies when observed by either conspecific. Future studies designed to dissociate the observer's behavior from the experience of having caches pilfered will be necessary to better understand whether pinyon jays can discriminate between pilfering and nonpilfering conspecifics.

Individual recognition may not be all that informative in some caching situations, as an observer's intent to pilfer may vary across situations due to intrinsic factors, such as hunger/ energy level or age, or environmental factors such as seasonality (e.g., when feeding offspring), population density or food abundance (Andersson \& Krebs, 1978; Donald \& Boutin, 2011; Lucas \& Zielinski, 1998; Vander Wall, 1990; Vander Wall \& Jenkins, 2003; also see van der Vaart, Verbrugge, \& Hemelrijk, 2012). Although individual recognition may facilitate cache sharing among closely related individuals, this possibility has not been examined - certainly, an intriguing issue to be examined with a species as highly social as the pinyon jay. 
Preferential allocation of seeds cached across all experimental conditions and blocks may suggest that cachers generally viewed the testing environment as "risky" for their caches, influencing the caching behavior of the individual even in the absence of an observing bird. This suggestion is also supported by the increase of recaching over time, as recaching is a common cache protection strategy used by corvids (e.g., Emery et al., 2004). Additional comparisons with baseline trials revealed that cachers increased the amount of caches made in the safe tray, especially when observed by another bird or in the presence of a taxidermy bird. This finding shows that cachers associated the safe tray as a location with low pilfering risk. When observed by another pinyon jay, individuals cached fewer seeds in the pilfered tray in comparison to when they were caching alone. This result indicates that individuals perceived the pilfered tray as a risky location to store their caches. Thus, when perceiving the caching environment as risky, pinyon jays modify their caching behavior by preferentially allocating a greater number of pine seeds in safe locations and fewer pine seeds in the more risky pilfered tray.

\section{Influence of caching experience}

Previous studies have shown that past experience being a pilferer can influence an individual's future caching behavior. Emery and Clayton (2001) and Clary and Kelly (2011) showed that when an individual was provided with an opportunity to pilfer the caches of a conspecific, the bird showed cache protection strategies when they later had an opportunity to cache themselves, whereas without this initial pilfering experience they did not. All the pinyon jays in our current study had previous experience having their caches stolen (Vernouillet, 2020), although none had experience being a pilferer themselves (in an experimental setting). During this previous study, the pinyon jays engaged in similar cache protection strategies as we report here, after one or two experiences having their caches stolen. This previous experience seems to have been sufficient to cause the birds to readily use these previously learned behaviors when experiencing pilfering events in the current study. Importantly, during the baseline trials of the current study, we did not see tray preferences, supporting that the birds used the information gained during the study to reinstitute their cache protection strategies. However, this initial experience may have biased the pinyon jays in our current study to generalize cache risk to the environment itself (as supported by an overall preference to cache in the safe tray), resulting in the engagement of cache protection strategies even in the presence of an unlikely threat, such as the inanimate heterospecific. Thus, it could be that pinyon jays need to learn that an inanimate object or heterospecific can be a threat, and our previous study provided them with this opportunity, and once learned this information is readily transferred to new situations. This suggestion is supported by the fact that we did not find any learning effects in the experiment, as there were no effects of block on the caching behavior of the pinyon jays. Future research examining whether the rate of learning to respond to human-made or naturalistic observers is similar to each other, would provide this necessary insight. Knowing how pinyon jays, and other food-storing animals, learn to discriminate between observers who are potential cache threats, from those who are not, will further enrich our understanding of the influence of a species' social ecology on the evolution of cognitive abilities.

Supplementary Information The online version contains supplementary material available at https://doi.org/10.3758/s13420-020-00450-5.

Author note The study reported here was in partial fulfillment of the requirements for a Bachelor of Science honors degree to Hera J. M. Casidsid. Research support was provided by a Natural Science and Engineering Research Council Discovery grant (RGPIN/4944-2017) and a Canada Research Chair to Debbie M. Kelly. Alizée Vernouillet is now a visiting research associate at the Department of Psychology at the University of Cambridge.

\section{References}

Andersson, M., \& Krebs, J. (1978) On the evolution of hoarding behaviour. Animal Behaviour, 26, 707-711.

Balda, R., \& Bateman, G. (1971). Flocking and annual cycle of the piñon jay, Gymnorhinus cyanocephalus. The Condor, 73(3), 287-302.

Bates, D., Maechler, M., Bolker, B., \& Walker, S. (2015). Fitting linear mixed-effects models using lme4. Journal of Statistical Software, $67,1-48$

Bednekoff, P. A., \& Balda, R. P. (1996). Social caching and observational spatial memory in pinyon jays. Behaviour, 133(11), 807-826.

Bugnyar, T. (2011). Knower-guesser differentiation in ravens: Others' viewpoints matter. Proceedings of the Royal Society B: Biological Sciences, 278, 634-640.

Bugnyar, T. (2013). Social cognition in ravens. Comparative Cognition \& Behavior Reviews, 8, 1-12.

Bugnyar, T., \& Heinrich, B. (2006). Pilfering ravens, Corvus corax, adjust their behavior to social context and identity of competitors. Animal Cognition, 9, 369-376.

Bugnyar, T., Schwab, C., Schloegl, C., Kotrschal, K., \& Heinrich, B. (2007). Ravens judge competitors through experience with play caching. Current Biology, 17, 1804-1808.

Clary, D., \& Kelly, D. M. (2011). Cache protection strategies of a nonsocial food-caching corvid, Clark's nutcracker (Nucifraga columbiana). Animal Cognition, 14, 735-744.

Clayton, N.S., Dally, J. \& Emery, N.J. (2007). Social cognition by foodcaching corvids: The western scrub-jay as a natural psychologist. Philosophical Transactions of the Royal Society B: Biological Sciences, 362, 507-522.

Clayton, N. S., \& Emery, N. J. (2008). The social life of corvids. Current Biology, 17, 652-656.

Curio, E., Ernst, U., \& Vieth, W. (1978). Cultural transmission of enemy recognition: One function of mobbing. Science, 202, 899-901.

Cussen, V. A. (2017). Psittacine cognition: individual differences and sources of variation. Behavioural Processes, 134, 103-109.

Dally, J. M., Emery, N. J., \& Clayton, N. S. (2004) Cache protection strategies by western scrub jays (Aphelocoma californica): Hiding 
food in the shade. Proceedings of the Royal Society B: Biological Sciences, 271, S380-S390.

Dally, J. M., Emery, N. J., \& Clayton, N. S. (2005) Cache protection strategies by western scrub-jays, Aphelocoma californica: Implications for social cognition. Animal Behaviour, 70, 1251-1263.

Dally, J. M., Emery, N. J., \& Clayton, N. S. (2006a). The behaviour and evolution of cache protection and pilferage. Animal Behaviour, 72, $13-23$.

Dally, J. M., Emery, N. J., \& Clayton, N. S. (2006b). Food-caching western scrub-jays keep track of who was watching when. Science, 312, 1662-1665.

Dally, J. M., Emery, N. J., \& Clayton, N. S. (2010). Avian theory of mind and counter espionage by food-caching western scrub-jays (Aphelocoma californica). European Journal of Developmental Psychology, 7, 17-37.

de Kort, S. R., \& Clayton, N. S. (2006). An evolutionary perspective on caching by corvids. Proceedings of the Royal Society B: Biological Sciences, 273, 417-423.

Donald, J. L., \& Boutin, S. (2011) Intraspecific cache pilferage by larderhoarding red squirrels (Tamiasciurus hudsonicus). Journal of Mammalogy, 92, 1013-1020.

Emery, N. J., \& Clayton, N. S. (2001). Effects of experience and social context on prospective caching strategies by scrub jays. Nature, 414(6862), 443-446. doi:https://doi.org/10.1038/35106560

Emery, N. J., \& Clayton, N. S. (2004). The mentality of crows: convergent evolution of intelligence in corvids and apes. Science, 306, 1903-1907.

Emery, N. J., \& Clayton, N. S. (2009). Comparative social cognition. Annual Review of Psychology, 60, 87-113.

Emery, N. J., Dally, J. M., \& Clayton, N. S. (2004). Western scrub-jays (Aphelocoma californica) use cognitive strategies to protect their caches from thieving conspecifics. Animal Cognition, 7(1), 37-43.

Gould, K. L., Kelly, D. M., \& Kamil, A. C. (2010). What scatter-hoarding animals have taught us about small-scale navigation. Philosophical Transactions of the Royal Society B: Biological Sciences, 1542, 901-914.

Humphrey, N. K. (1976). The social function of intellect. In P. P. G. Bateson \& R. A. Hinde (Eds.), Growing points in ethology (pp. 307-317). Cambridge, UK: Cambridge University Press.

Kondo, N., Izawa, E.-I. \& Watanabe, S. (2012). Crows cross-modally recognize group members but not non-group members. Proceedings of the Royal Society B: Biological Sciences, 279, 1937-1942.

Lambert, M., Jacobs, I., Osvath, M., \& von Bayern, A. M. P. (2018). Birds of a feather? Parrot and corvid cognition compared. Behaviour, 156, 505-594.

Legg, E. W., \& Clayton, N. S. (2014). Eurasian jays (Garrulus glandarius) conceal caches from onlookers. Animal Cognition, 17, $1223-1226$

Lenth, R. V. (2016). Least-squares means: The R package lsmeans. Journal of Statistical Software, 69, 1-33.

Lucas, J. R., \& Zielinski, D. L. (1998). Seasonal variation in the effect of cache pilferage on cache and body mass regulation in Carolina chickadees: What are the trade-offs? Behavioral Ecology, 9, 193-200.

Marzluff, J. M., \& Balda, R. P. (1992). The pinyon jay: Behavioral ecology of a colonial and cooperative corvid. London, UK: T \& AD Poyser.

Maziarz, M., Piggott, C., \& Burgess, M. (2018). Predator recognition and differential behavioural responses of adult wood warblers Phylloscopus sibilatrix. Acta Ethologica, 21, 13-20.

Paz-y-Mino, G., Bond, A. B., Kamil, A. C., \& Balda, R. P. (2004). Pinyon jays use transitive inference to predict social dominance. Nature, 430, 778-781.

Pepperberg, I. M. (1990). Cognition in an African gray parrot (Psittacus erithacus): Further evidence for comprehension of categories and labels. Journal of Comparative Psychology, 104, 41-52.
Pepperberg, I. M. (2006a). Ordinality and inferential abilities of a grey parrot (Psittacus erithacus). Journal of Comparative Psychology, 120, 205a-216.

Pepperberg, I. M. (2006b). Grey parrot numerical competence: review. Animal Cognition, 9, 377-391.

Pepperberg, I. M. (2013). Abstract concepts: Data from a grey parrot. Behavioural Processes, 93, 82-90.

Pravosudov, V. V. (2008). Mountain chickadees discriminate between potential cache pilferers and non-pilferers. Proceedings of the Royal Society B: Biological Sciences, 275, 55-61.

Pravosudov, V. V., \& Smulders, T. V. (2010) Integrating ecology, psychology and neurobiology within a food-hoarding paradigm. Philosophical Transactions of the Royal Society B: Biological Sciences, 365, 859-867.

Revelle, W. R. (2017). Psych: Procedures for personality and psychological research [Computer software]. Evanston, IL: Northwestern University. Retrieved from https://CRAN.R-project.org/package=psych

Shaw, R. C., \& Clayton, N. S. (2012). Eurasian jays, Garrulus glandarius, flexibly switch caching and pilfering tactics in response to social context. Animal Behaviour, 84, 1191-1200.

Shaw, R. C., \& Clayton, N. S. (2013) Careful cachers and prying pilferers: Eurasian jays (Garrulus glandarius) limit auditory information available to competitors. Proceedings of the Royal Society B: Biological Sciences, 280, 2012238.

Shettleworth, S. J. (2010). Clever animals and killjoy explanations in comparative psychology. Trends in Cognitive Sciences, 14, 477-481.

Spiess, A.N. (2018). qpcR: Modelling and analysis of real-time PCR data [Computer software]. Retrieved from https://CRAN.R-project.org/ package $=q p c R$

Tornick, J. K., Rushia, S. N., \& Gibson, B. M. (2016). Clark's nutcrackers (Nucifraga columbiana) are sensitive to distance, but not lighting when caching in the presence of a conspecific. Behavioural Processes, 123, 125-133.

van der Vaart, E., Verbrugge, R., \& Hemelrijk, C. (2012). Corvid recaching without 'theory of mind': A model. PLOS ONE, 7, e32904.

Vander Wall, S. B. (1990). Food hoarding in animals. Chicago, IL: University of Chicago Press.

Vander Wall, S. B., \& Jenkins, S. (2003) Reciprocal pilferage and the evolution of food-hoarding behavior. Behavioral Ecology, 14, 656-667.

Vernouillet, A. (2020). The influence of the social environment on exploration and caching behaviour in highly social pinyon jays and less social Clark's nutcrackers (Doctoral dissertation). Retrieved from http://hdl.handle.net/1993/34648

Vernouillet, A., \& Kelly, D. M. (2020). Individual exploratory responses are not repeatable across time or context for four species of foodstoring corvid. Scientific Reports, 10, 1-11.

Yorzinski, J. L. (2017). The cognitive basis of individual recognition. Current Opinion in Behavioral Sciences, 16, 53-57.

Zandberg, L., Jolles, J. W., Boogert, N. J., \& Thornton, A. (2014). Jackdaw nestlings can discriminate between conspecific calls but do not beg specifically to their parents. Behavioral Ecology, 25, 565-573.

Open practices statement Data are available as supplementary material. The experiment was not preregistered.

Publisher's note Springer Nature remains neutral with regard to jurisdictional claims in published maps and institutional affiliations. 